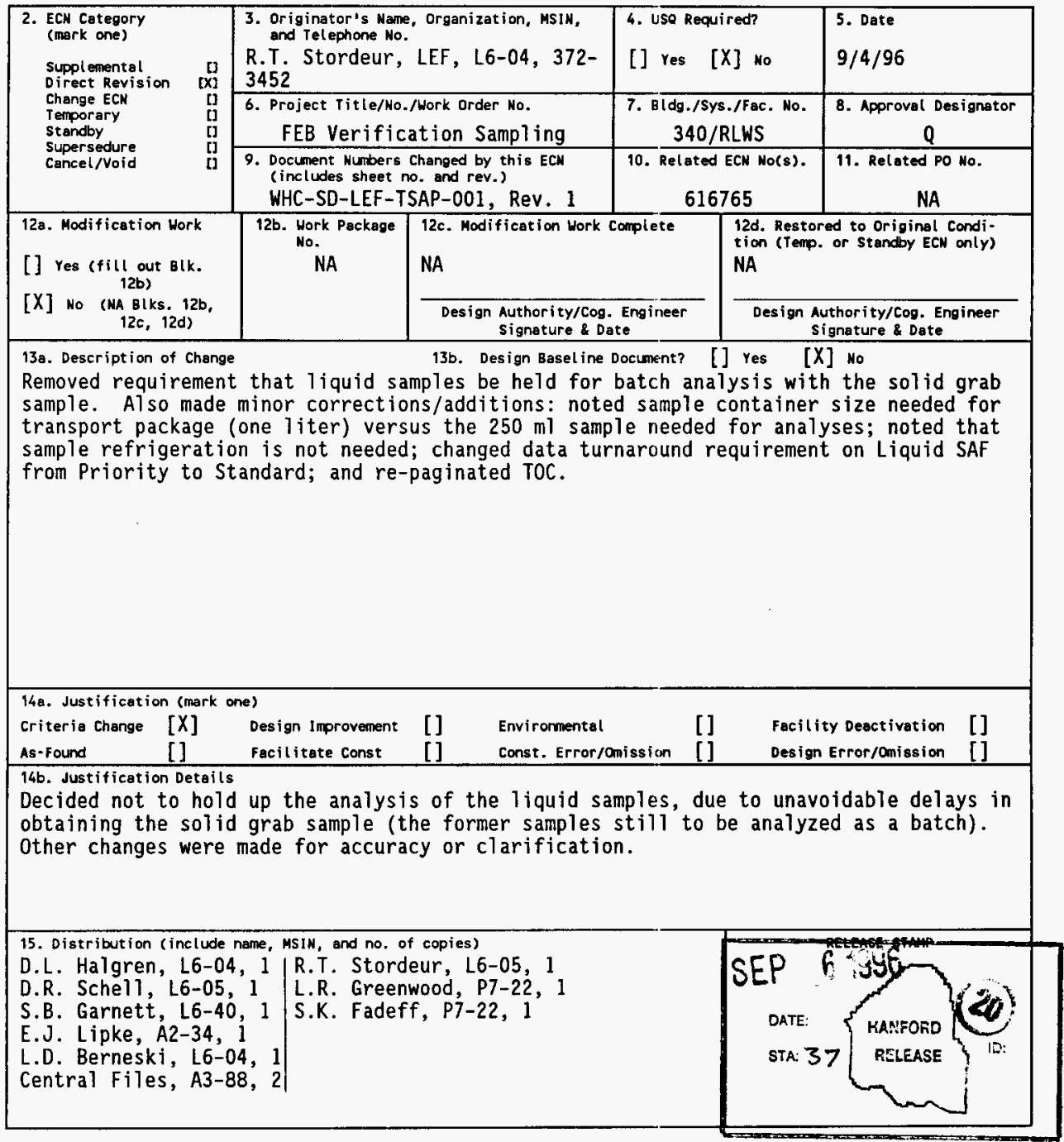




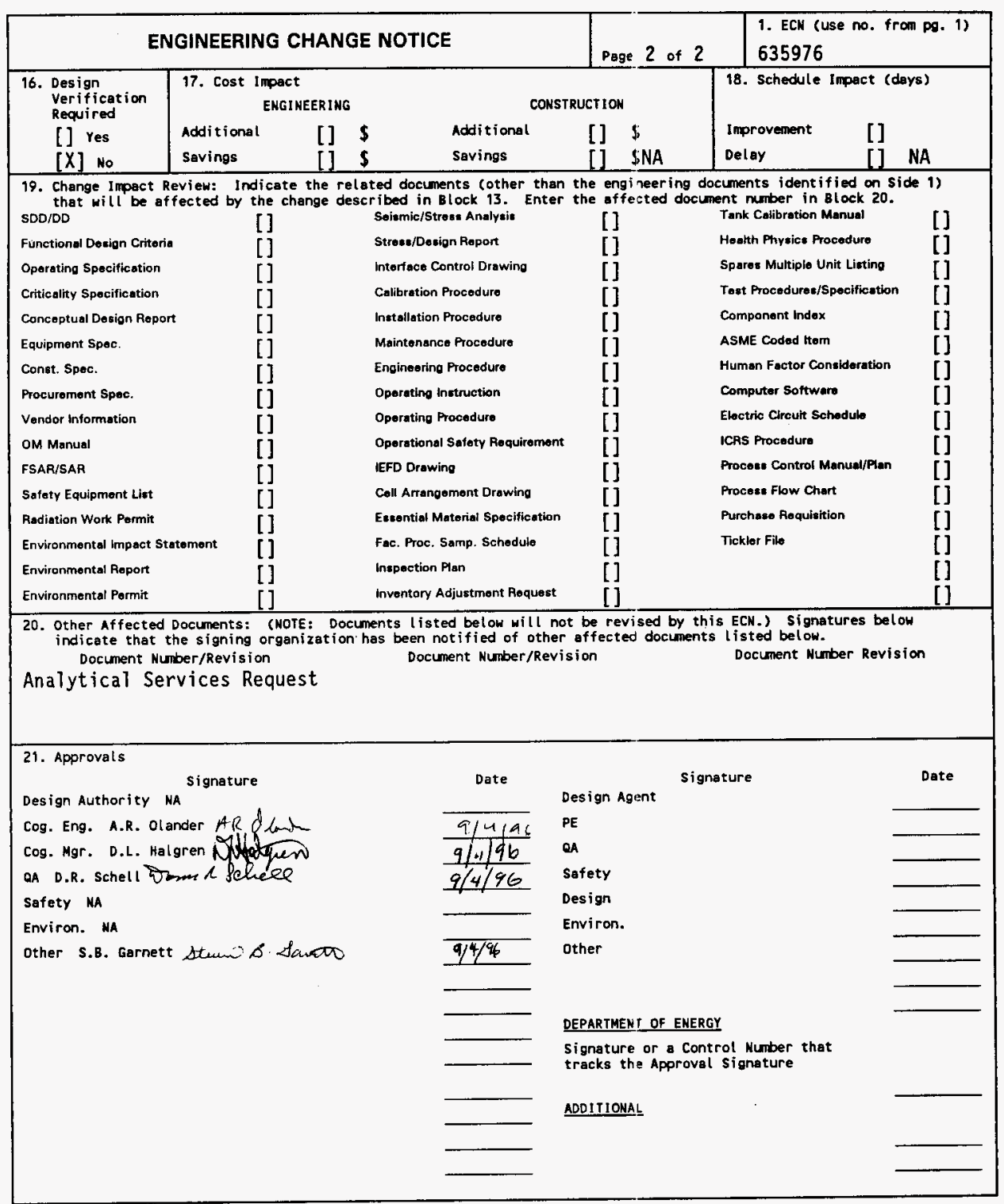




\title{
340 REPRESENTATIVE SAMPLING VERIFICATION TANK SAMPLING AND ANALYSIS PLAN
}

\author{
A.R. 01 ander \\ Westinghouse Hanford Company, Richland, WA 99352 \\ U.S. Department of Energy Contract DE-AC06-87RL10930
}

ECN: 635976

Org Code: 86730

B\&R Code: 39EW31302
UC: 2020

Charge Code: A234X

Total Pages: 15

Key Words: 340 Facility, Vault Tank, Sampling and Analysis Plan, Characterization.

Abstract: This Sampling and Analysis Plan contains requirements for characterizing the 340 vault tank 1 . The objective of the sampling and characterization is to determine if the tank is homogeneous when agitated and which sampling method provides the most representative sample. A secondary objective is to collect and characterize solid samples.

TRADEMARK DISCLAIMER. Reference herein to any specific commercial product, process, or service by trade name, trademark, manufacturer, or otherwise, does not necessarily constitute or imply its endorsement, recomendation, or favoring by the United States Government or any agency thereof or its contractors or subcontractors.

Printed in the United states of America. To obtain copies of tmis document, contact: WHC/BCS Document Control Services, P.O. BOx 1970, Mailstop H6-08, Richl and WA 99352, Phone (509) 372-2420; Fax (509) 376-4989.
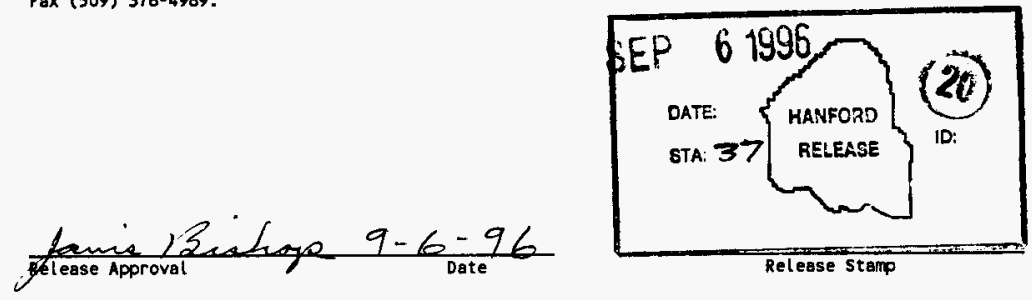

\section{Approved for Public Release}




\section{RECORD OF REVISION}

(1) Document Number

WHC-SD-LEF-TSAP001

(2) Title

340 Representative Sampling Verification Tank Sampling and Analysis Plan CHANGE CONTROL RECORD

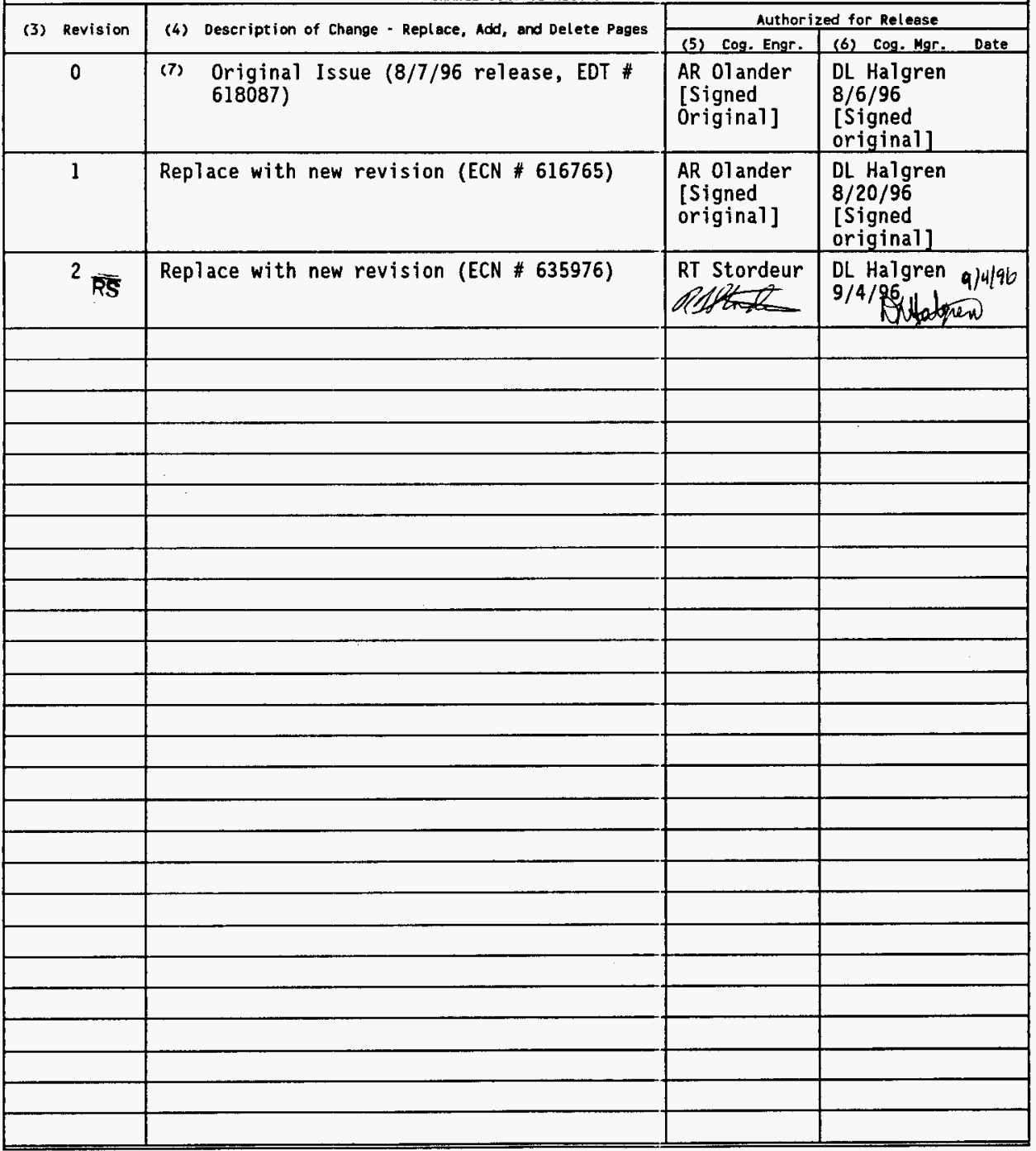


WHC-SD-LEF-TSAP-001, Rev. 2

340 Representative Sampling Verification

Tank Sampling and Analysis Plan 
WHC-SD-LEF-TSAP-001, Rev. 2

Table of Contents

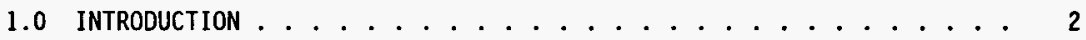

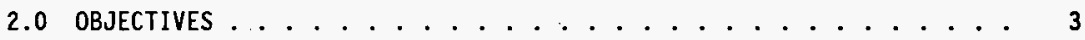

3.0 ReSPONSIBILITIES . . . . . . . . . . . . . . . 4

4.0 SAMPLING LOCATION AND QUANTITY ............... 5

5.0 SAMPLE IDENTIFICATION ......................... 6

6.0 SAMPLING EQUIPMENT AND PROCEDURES .............. 6

7.0 SAMPLE HANDLING AND ANALYSIS .............. 8

8.0 QUALITY ASSURANCE PROJECT PLAN ............. 8

8.1 QUALITY CONTROL OF FIELD ACTIVITIES $\ldots . \ldots . \ldots 9$

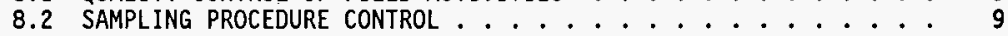

8.3 LABORATORY QUALITY CONTROL $\ldots \ldots \ldots \ldots . \ldots . \ldots . \ldots . \ldots 9$

8.4 DATA QUALITY OBJECTIVES ................. 12

8.5 QUALITY ASSURANCE OBJECTIVES ........ 12

8.6 DATA REDUCTION, VALIDATION, AND REPORTING $\ldots \ldots \ldots$

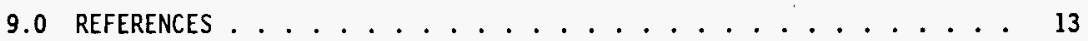




$$
\text { WHC-SD-LEF-TSAP-001, Rev. } 2
$$

\subsection{INTRODUCTION}

Concerns have been raised about possible accumulation of fissile material in the vault tanks and whether or not sampling methods are representative of tank contents. This characterization effort will be designed to collect samples from various locations in the tank for comparison.

This Sampling and Analysis Plan (SAP) describes the field activities and methods associated with collection of radioactive wastewater samples from the 340 vault tanks. Sampling location and number are specified in this SAP, as are work plans and procedures for packaging the samples and transporting them to the 325 Building for analysis.

The remaining sections of this SAP include the following:

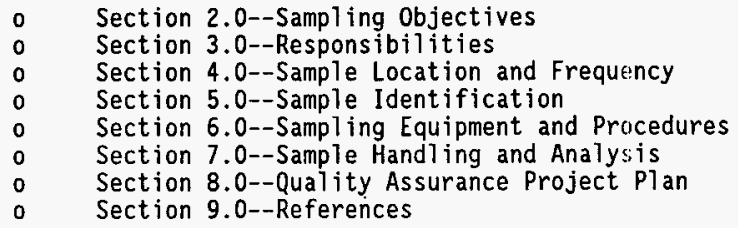

The Quality Assurance Project Plan (QAPP) provides the guidelines and requirements enhance the quality of the radioactive liquid effluent sampling activities.

System Description The vault tanks are 14' diameter 13'1" high stainless steel accumulation tanks. The tanks are sloped 1/8" per foot towards a $3^{\prime \prime}$ drain pipe with a blind flange. The drain pipe is at the periphery of the tank near the vault sump. The vault sump is at the center of the vault between the tanks. Each tank has 3 equally spaced baffles that are $3 / 8$ " thick, $10^{\prime \prime}$ wide and 10'6" tall. The bottoms of the baffles are 9" from the bottom of the tank. The baffles are attached to the tank with

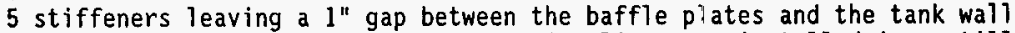
along most of the length. Instrumentation lines are installed in a stilling chamber in each tank. The stilling chamber is a $6^{\prime \prime}$ line with $1 / 2$ " holes. In vault tank 1, a manometer line in the stilling chamber has been converted to a sample line. The tanks are also equipped with cooling jackets and immersion heaters that are no longer in service. 
WHC-SD-LEF-TSAP-001, Rev. 2

Vault tank equipment includes sump pumps, a backup transfer/sample pump, and mixers. Each tank has one sump pump that is used to transfer waste between vault tanks, to the above ground storage tanks, or to the railcar. The sump pumps bell housings are 12" from the bottom of the tank. The pumps are rated at $100 \mathrm{gpm}$ with $53^{\prime}$ Total Discharge Head (TDH). The backup pump is a centrifugal pump rated at $150 \mathrm{gpm}$ at $60^{\circ} \mathrm{TDH}$. The suction leg for the pump is a 4" Tine that is 4" from the bottom of the tank. Each tank has a 15 horse power mixer. The impeller has 6 blades that are 14" from the bottom of the tank and are designed to turn at $68 \mathrm{rpm}$.

The tank mixers are located in the center of tank. The sump pumps are 4'8" from the center. The suction leg for the backup transfer/sample pump is 6 ' 6" from the center of the tank on the opposite side of the tank from the sump pumps.

\subsection{OBJECTIVES}

Overall objectives for the SAP are to provide data that will identify reliable and repeatable methods for collecting representative samples from different locations in the vault tanks. Solid samples will also be collected from the tank bottom to determine the type of solids that may have accumulated. The sample analytical results will be compared to determine if the waste is homogeneous.

Liquid samples will be collected from the bottom of the tank using two separate systems if possible; sample collection using TP-3 is not reliable. The suction head of the pump is not always adequate to 1 ift the waste for sampling. If functioning properly, more than one sample will be collected using TP-3 and more than one sample will be collected using the alternate method. Samples collected using each method can be compared to determine natural system variation. Samples collected using IP-3 can be compared against each other and then can be compared against the samples collected using the alternate method.

Other samples will be collected from a transfer pipe sample tap at different times during railcar filling. If the waste has the same composition at the beginning and end of the transfer then the tank was well mixed. These results will be compared against each other and samples collected from the bottom of the tank.

All Personnel associated with collection of liquid effluent characterization samples, processing of the samples, processing of the data, and control of records shall comply with the procedures related to their responsibilities. As necessary, personnel shall sign a document verifying that they have read and understand the procedures.

The samples will also be analyzed for radionuclides of concern for fissile tracking and soluble radionuclides that may provide an indication of sampling precision. 


\section{WHC-SD-LEF-TSAP-001, Rev. 2}

\subsection{RESPONSIBILITIES}

The organizations listed below have the following responsibilities for implementation of this SAP.

Process Engineering

- Provides Person in Charge (PIC)/operator support as required during liquid effluent characterization sampling including sampler setup.

- Coordinates Health Physics Technician support.

o Writes sampling and analysis plans and maintenance work plans for preparing vault tanks for characterization activities.

- Prepare statement of work and select contract 1aboratory.

- Schedule and prioritize sample analyses requests.

o Coordinate sampling and laboratory analysis schedule.

o File "chain-of-custody" documentation received from samples.

$0 \quad$ Work Control and Data Management.

OPERATIONS

0 Approve the SAP/QAPP.

- Sample tanks and control samples until delivered to the laboratory.

- Package samples for shipment.

- Transport samples to the analytical laboratory or shipping center.

- Document sampling activities in a controlled log book.

- Initiate "chain-of-custody" documentation for samples.

- Store controlled field logs and other sampling data information. 


$$
\text { WHC-SD-LEF-TSAP-001, Rev. } 2
$$

Health and Safety

- Provide the Radiation Work Permit instructions for radiation area entry.

- Verify radiation worker training requirements of sampling personnel.

Quality Assurance (QA)

0 Review and approve this SAP/QAPP.

$0 \quad$ Audit records and procedures.

\subsection{SAMPLING LOCATION AND QUANTITY}

Vault tank 1 waste will be sampled at 4 locations. Two sample sets will be collected from different locations at the bottom of the tank using routine sampling procedures. Two sample sets will be collected from the transfer piping as the railcar is loaded. One sample set will be collected from the bottom of the tank from an available access port.

TP-3/Primary Sample Location The primary sampling system uses a recirculation 10op, centrifuga 7 pump, sample line, and sample hood. After the waste is agitated for 55 minutes, waste is drawn up through a 4" pipe that is 6'6" from the center of the tank. The bottom of the suction line is 4" from the bottom of the tank. When the system is operated, the waste is drawn up through the suction pipe through valve RL-6 into TP-3 out through RL-11 and RL-14 and through RL-8 back into vault tank 1. A 1/2" sample line is connected to the 4" recycle loop between valves RL-11 and RL-14. When RL-13 and RL-13A are opened waste is pushed through the sample loop and back into the vault tank. The sample line is $1 / 2$ " stainless steel. From the recycle loop to the sample collection point in the hood, the sample line spans approximately $25^{\prime}$ horizontal and $15^{\prime}$ vertical distance. A sample is collected by opening valve RL-13B in the decontamination area sample hood.

Alternate Sample Location The alternate sample system was installed as a backup to the primary (TP-3) system. The system was tied into a stilling chamber which is $6^{\prime} 3^{\prime \prime}$ from the center of the tank. The stilling chamber is a 6 " stainless steel pipe with 1/2" holes on 6" vertical centers. A number of instrumentation lines are inside the stilling chamber. The alternate sample line is tied into a 1/2" 1 ine that was formerly used for a manometer. The bottom of the line is 13" from the bottom of the tank. The line from the top of the tank is 1/2" stainless steel and spans approximately 25' horizontal and $10^{\prime}$ vertical distance to the sample collection point. After the waste is agitated for 55 minutes, the sample is collected by attaching a vacuum flask and vacuum pump to the sample line. 
Transfer Pipe Sample Location Grab samples will be collected from transfer piping on the load-out platform. A flange with sample tap will be installed so samples can be collected while the railcar is being filled. The flange attachment is in the last $5^{\prime}$ of hard pipe. After the hard pipe, the waste flows into about $15^{\prime}$ of flex pipe and then into the railcar. Samples will be collected during the first 20 minutes of load-out and during the last twenty minutes. The time expected to fill the railcar is approximately 60 minutes. The agitator normally runs during the entire load-out. Occasionally, to minimize the heel, the mixer is turned off and the waste is pumped below the impeller. Samples will only be collected while the agitator is operating.

Solid Sample The sample of accumulated bottom solids will be collected from an undetermined access port. It may be necessary to remove instrumentation temporarily from a port to make room for the sampling activity. The location of the port is not important to the sampling activity. The goal of the sampling is to collect any solid material existing at the bottom of the tank. The agitator will not be run prior to sampling for solids. Using a rigid pole, a sample scoop will be moved across the botton to collect any heavy solid material that has accumulated. The amount of solids will provide a very rough quantitative estimate of solids that have acc umulated, but the primary purpose is to determine the type of solids.

Sample Quantity More than one sample should be collected from each sample location. The initial goal should be to collect 2 samples from each location. More can be collected and will be analyzed if a need exists.

Table l summarizes the characterization strategy.

\subsection{SAMPLE IDENTIFICATION}

Sample identification numbers shall be furnished by process engineering. The labels will also require the following information to be recorded by a member from the sampling team: sampler's initials; date and time the sample was collected; the place the sample point; and the analysis to be performed on the sample. Details of the analysis to be performed will be included on the Sampling and Analysis Form (SAF). The sample labels shall reference the appropriate SAF.

\subsection{SAMPLING EQUIPMENT AND PROCEDURES}

The sampling equipment is described in 2 operating procedures and a maintenance work plan. There are procedures for sampling from the vault tank using TP-3 and the alternate method. A maintenance work plan has been written for collecting grab samples from the top, mid-level, and bottom of the tank. Following are procedure and work plan numbers and titles specific to each sample location:

Document Number
$340-0 P-007$
$340-0 P-008$
$3 D-96-0072$
$340-0 P-001$

$\frac{\text { Document Number }}{340-0 \mathrm{P}-007}$

340-0P-008

$340-0 P-001$
Title

Sample RLW From Vault Tanks

Sample Vault Tanks - Alternate Sampling Method

Sludge Sample from TK-1

Transfer RLW to Railroad Tank Car 
WHC-SD-LEF-TSAP-001, Rev. 2

Table 1. Characterization Sample Summary

\begin{tabular}{|c|c|c|c|}
\hline $\begin{array}{c}\text { Sample } \\
\text { Location/Method }\end{array}$ & Waste Phase & Sample Quantity & Analysis \\
\hline $\begin{array}{l}\text { Bottom of } \\
\text { Tank/TP-3 }\end{array}$ & $\begin{array}{l}\text { Mostly liquid } \\
\text { with some solids }\end{array}$ & More than one & $\begin{array}{c}\text { Plutonium } \\
\text { Isotopic } \\
\text { Uranium I sotopic } \\
\text { GEA } \\
\text { Percent Solids } \\
\text { pH } \\
\text { SpG }\end{array}$ \\
\hline $\begin{array}{c}\text { Bottom of } \\
\text { Tank/Alternate } \\
\text { Method }\end{array}$ & $\begin{array}{l}\text { Mostly liquid } \\
\text { with some solids }\end{array}$ & More than one & $\begin{array}{c}\text { PTutonium } \\
\text { Isotopic } \\
\text { Uranium Isotopic } \\
\text { GEA } \\
\text { Percent Solids } \\
\text { pH } \\
\text { SpG }\end{array}$ \\
\hline $\begin{array}{l}\text { Transfer } \\
\text { Start/Grab }\end{array}$ & $\begin{array}{l}\text { Mostly liquid } \\
\text { with some solids }\end{array}$ & More than one & $\begin{array}{c}\text { Plutonium } \\
\text { Isotopic } \\
\text { Uranium Isotopic } \\
\text { GEA } \\
\text { Percent Solids } \\
\text { pH } \\
\text { SpG }\end{array}$ \\
\hline $\begin{array}{l}\text { Transfer } \\
\text { End/Grab }\end{array}$ & $\begin{array}{l}\text { Mostly liquid } \\
\text { with some solids }\end{array}$ & More than one & $\begin{array}{c}\text { PTutonium } \\
\text { Isotopic } \\
\text { Uranium Isotopic } \\
\text { GEA } \\
\text { Percent Solids } \\
\text { pH } \\
\text { SpG }\end{array}$ \\
\hline $\begin{array}{l}\text { Bottom of } \\
\text { Tank/Grab }\end{array}$ & $\begin{array}{c}\text { Mostly solids } \\
\text { with incidental } \\
\text { liquid }\end{array}$ & More than one & $\begin{array}{c}\text { Plutonium } \\
\text { Isotopic } \\
\text { Uranium Isotopic } \\
\text { Fissionable } \\
\text { Material } \\
\text { GEA } \\
\text { SpG } \\
\end{array}$ \\
\hline
\end{tabular}




\subsection{SAMPLE HANDLING AND ANALYSIS}

Once a liquid sample has been drawn, it must be in the physical control or view of the custodian, located in an area where it cannot be tampered with or prepared for shipping with tamper-proof tape applied. If the samples are to be left unattended, physical control will be maintained by placing samples in the sample hood with tamper tape. When more than one person is involved in sampling, one person shall be designated and only that person signs as sampler. This person is the custodian until the samples are transferred to another location or group and shall sign when releasing the samples to the designated receiver.

The samples will be packaged for shipment per procedure 340-0P-021, Package/Transport RLW Samples Using Hedgehog System. After packaging, the samples will be hand carried to the 325 Building for analysis. At the laboratory, the sample custodian or his alternate shall sign and date all appropriate receiving documents at the time of receipt and at the same time initiate an internal Chain of Custody form using documented procedures. A continuous chain of custody will be maintained from the time of sampling until final disposition of all samples.

Each liquid sample will be analyzed for $\mathrm{pH}$, percent solids, plutonium, uranium, and gamma emitting radionuclides. The solids will be dissolved and analyzed with the liquid. The bottom of the tank solids will be separated and analyzed separately from any incidental liquid collected. The SAFs list specific procedures and requirements for the liquid and solids analysis and are shown as Figures 1 and 2.

Certified clean containers will not be necessary for this characterization project; radionuclide contamination is not anticipated on commercially available sample bottles. A nitric acid preservative will not be used in the sample containers, nor is refrigeration required. For the liquid samples acidification would invalidate the percent solids analysis. Plastic samples bottles will be used; plutonium sticks more readily to glass containers.

\subsection{QUALITY ASSURANCE PROJECT PLAN}

This job specific QAPP provides the general framework for sample collection, laboratory analysis, and data reporting. The QAPP covers QA requirements for the characterization of the vault tanks. These QA requirements include sample collection, sample control, data quality objectives (DQOS), laboratory analysis, and data reporting.

In addition to the project plan, there are several upper tier documents applicable to this characterization activity. Activities at the 340 Waste Handling Facility are implemented under an organization specific Quality Assurance Program Plan. The Quality Assurance Program Plan for the 300 Area Liquid Effluent Facilities can be found in WHC-IP-1000, 300 Area Liquid Effluent Facilities Administrative, Section 1.4, Parts 4.6.1, "Engineering Documents"; Section 4.6.3, "Operating Procedures"; and Section 4.13, "Handling, Storage, and Shipping" provides applicable guidance to this characterization activity. 


\subsection{QUALITY CONTROL OF FIELD ACTIVITIES}

Audits of sampling activities have been periodically performed in the past. Due to the large number of samples and importance of the characterization project $Q A / Q u a l i t y$ Control (QC) field presence will be required. Specifically, QA/QC will be requested at a minimum to verify the following:

- Sample Piping has been properly purged.

- Samples have been correctly identified.

\subsection{SAMPLING PROCEDURE CONTROL}

Operating procedures and maintenance work procedures are controlled according to the requirements contained in the WHC-IP-1000. The requirements of operating procedure control are listed in Section 3.1, "Technical Procedure Control Process". Maintenance work plans control requirements are in Section 4, "Work Control".

\subsection{LABORATORY QUALITY CONTROL}

The Quality Assurance Plan (QAP) for the Analytical Chemistry Laboratory (325) is MCS-033, Quality Assurance Plan for Activities Conducted by the Analytical Chemistry Laboratory Revision 4, Section 9.4, identifies "Radiochemical Quality Control". The QAP was prepared following guidance from Interim Guidelines and Specifications for Preparing QAPP, USEPA Office of Monitoring Systems and Quality Assurance Office of Research and Development (QAMS-005/80). The identifies controls and requirements for all aspects of characterization work.

Two key elements of QA within the 325 Laboratory are the assignment of a Project Manager (PM) and impact level.

L.R. Greenwood is the PM for this characterization project. Some of his responsibilities include acting as a single point of contact, development of appropriate DQOS, and ensuring analytical staff is provided the necessary information to meet data quality requirements.

The impact level designation is a risk-based rating system with Levels I, II, and III. The severest health and safety or technical risk work if predetermined goals are not accomplished is impact Level I. Impact Level II analytical work provides the same rigor as impact Level I, but the QA details are not included in the final report. Even though duplicate test and other data is not in the final report, qualified data would be flagged. Impact Level II has been selected for this project. 
Figure 1. Liquid SAF

\begin{tabular}{|c|c|c|c|c|}
\hline \multicolumn{4}{|c|}{ Sampling Authorization Form } & \multirow{2}{*}{$\begin{array}{c}\text { Crit-L } \\
\begin{array}{c}\text { Holding } \\
\text { Time }\end{array}\end{array}$} \\
\hline $\begin{array}{c}\text { Parameter/ } \\
\text { Analys is }\end{array}$ & $\begin{array}{l}\text { Analytical } \\
\text { Methods }\end{array}$ & $\begin{array}{c}\text { Container/ } \\
\text { Volume }\end{array}$ & Preservation & \\
\hline Vol \% Solids & PNL-AL0-504 & \multirow{8}{*}{$\begin{array}{c}\text { Plastic l } \\
\text { liter (use } \\
\text { HDPE or FEP } \\
\text { for transport } \\
\text { package) / at } \\
\text { least } 250 \mathrm{ml} \\
\text { sample }\end{array}$} & \multirow[t]{8}{*}{ NA } & ASAP \\
\hline $\mathrm{pH}$ & PNL-ALO-225 & & & ASAP \\
\hline SpG & PNL-ALO-535 & & & ASAP \\
\hline $\begin{array}{l}\text { Pu-238, } \\
239 / 240,241, \\
242\end{array}$ & PNL-ALO-455 & & & 6 Months \\
\hline $\begin{array}{l}\text { Pu Alpha } \\
\text { Energy }\end{array}$ & PNL-ALO-417 & & & 6 Months \\
\hline GEA & PNL-AL0-450 & & & 6 Months \\
\hline Total Uranium & PNL-AL0-445 & & & 6 Months \\
\hline $\begin{array}{l}\text { Uranium } \\
\text { Isotopic }\end{array}$ & PNL-AL0-455 & & & 6 Months \\
\hline
\end{tabular}

Data Turnaround Requirements: Standard

Quality Assurance: QA MCS 033, PNL Impact Level II

Data Deliverable: Level I

Special Instructions: Handle all Crit-L samples as a single batch 
Figure 2. Solid SAF

\begin{tabular}{|c|c|c|c|c|}
\hline \multicolumn{4}{|c|}{ Sampling Authorization Form } & Crit-s \\
\hline $\begin{array}{c}\text { Parameter/ } \\
\text { Analys is }\end{array}$ & $\begin{array}{c}\text { Analytical } \\
\text { Methods }\end{array}$ & $\begin{array}{c}\text { Container/ } \\
\text { Volume }\end{array}$ & Preservation & $\begin{array}{c}\text { Holding } \\
\text { Time }\end{array}$ \\
\hline $\begin{array}{l}\text { Pu-238, } \\
239 / 240,241, \\
242\end{array}$ & PNL-ALO-455 & \multirow{7}{*}{$\begin{array}{c}\text { Plastic 1 } \\
\text { liter (use } \\
\text { HDPE or FEP } \\
\text { for transport } \\
\text { package) / at } \\
\text { least } 250 \text { ml } \\
\text { sample }\end{array}$} & \multirow[t]{7}{*}{ NA } & 6 Months \\
\hline $\begin{array}{l}\text { Pu Alpha } \\
\text { Energy }\end{array}$ & PNL-ALO-417 & & & 6 Months \\
\hline Spg & PNL-ALO- 535 & & & ASAP \\
\hline Am-241 & $\begin{array}{l}\text { PNL-ALO- } \\
489 / 422 \\
\end{array}$ & & & 6 Months \\
\hline GEA & PNL-ALO-450 & & & 6 Months \\
\hline Total Uranium & PNL-AL0-445 & & & 6 Months \\
\hline $\begin{array}{l}\text { Uranium } \\
\text { Isotopic }\end{array}$ & PNL-ALO-455 & & & 6 Months \\
\hline
\end{tabular}

Analytical Protocols: RCRA

Data Turnaround Requirements: Standard

Quality Assurance: QA MCS 033, PNL Impact Level II

Data Deliverable: Level I

Special Instructions: None 
WHC-SD-LEF-TSAP-001, Rev. 2

\subsection{DATA QUALITY OBJECTIVES}

To prove samples are homogeneous there should only be statistically insignificant difference between samples collected at various locations. The samples collected will likely contain soluble and insoluble constituents. Separate liquid phases are not anticipated. The analysis results from soluble radionuclides will be compared as will the results from insoluble radionuclides. The laboratory results shall be within a $95 \%$ confidence interval.

\subsection{QUALITY ASSURANCE OBJECTIVES}

The QA standards for the 325 Laboratory are summarized in Table 9.8 of MCS-033. In order to ensure high quality data for this project, the 340 liquid samples shall be treated as a batch. This will ensure proper checks and controls are consistently performed during sample analysis; providing assurance of high quality data.

\subsection{DATA REDUCTION, VALIDATION, AND REPORTING}

The standard process for data checking at the 325 Laboratory is peer review. An independent $Q A$ review service is available, but is not required for this project. Reporting requirements for the 325 Laboratory are listed in Section 12.0 of MCS-033. For the purposes of this project, Data Deliverable Level $I$ is adequate. 


\subsection{REFERENCES}

(1) WHC-IP-1000, 300 Area Liquid Effluent Facilities Administration.

(2) MCS-033, Quality Assurance Plan for Activities Conducted by the Analytical Chemistry Laboratory (ACL), Revision 4, Issued May 31, 1996. 